\title{
FAKTOR - FAKTOR YANG BERHUBUNGAN DENGAN KEJADIAN ANEMIA PADA IBU HAMIL DI WILAYAH KERJA PUSKESMAS TANJUNG PINANG TAHUN 2018
}

\author{
Putri Dewi Anggraini \\ Email : Pu_3dewi@yahoo.com
}

\begin{abstract}
Iron deficiency anemia is anemia caused by the decrease in the total amount of iron in the body so that the reduced iron reserves. Based on the profile of Jambi City Health Department In 2017, the number of pregnant women in 20 healthcentercare the city of Jambi Tanjung Pinang PH Chas priority anemia ( $\mathrm{Hb}$ $<11 \mathrm{~g} \%)$ the highest of $168(19.5 \%)$ of pregnant women.

This research is descriptive analytic with cross sectional design. The purpose of this study was to look at the factors associated with anemia in pregnant women in the region work Puskesmas Tanjung Pinang 2018.

Research results obtained from 40 respondents, that the proportion of anemic pregnant womenat high riskbased ona parityof $55 \%$, high risk pregnancy spacing is $57.5 \%$, and consumption is less good fetabletis $19.23 \%$. Results of bivariate analysis there are three variables that had a significant relationship with anemia that is parity (0.002), spacing pregnancies $(0,001)$, and the tablet consumption fe $(0,022)$.

Based on the resultsof this study concluded that there was a significant relationship between parity, spacing pregnancies and Fe tablet consumption with incidence of anemia in pregnant women in Puskesmas Tanjung Pinang 2018.

Kata Kunci : Anemia dan Ibu Hamil

DIII Kebidanan Akademi Kebidanan Jakarta Mitra Sejahtera

Anemia pada kehamilan adalah anemia karena kekurangan zat besi, anemia defisiensi besi pada wanita hamil merupakan problema kesehatan yang dialami oleh wanita diseluruh dunia terutama dinegara berkembang. Badan kesehatan dunia (World Health Organization $=$ WHO) melaporkan bahwa ibu-ibu hamil yang mengalami defisiensi besi sekitar $35-75 \%$ serta

semakin meningkat seiring dengan bertambahnya usia kehamilan. Menurut WHO 40\% kematian ibu dinegara berkembang berkaitan dengan anemia pada kehamilan disebabkan oleh defisiensi besi dan perdarahan akut. Hasil persalinan pada wanita hamil yang menderita anemia defisiensi besi adalah 12-28\% angka kematian janin, $30 \%$ kematian
\end{abstract}


perinatal dan 7-10\% angka kematian neonatal (Proverawati, dkk. 2010).

Berdasarkan data dari hasil Survei Demografi dan Kesehatan Indonesia (SDKI, 2012), angka kematian ibu (AKI) melonjak drastis 359 per 100.000 kelahiran hidup. Beberapa penyebab langsung kematian ibu di Indonesia masih didominasi oleh perdarahan (42\%), eklampsia (13\%), dan infeksi (10\%). Anemia dan kekurangan energi kronik pada ibu hamil menjadi penye-bab utama terjadinya perdarahan dan infeksi. Tujuh dari sepuluh wanita hamil di Indonesia mengalami anemia. Hasil penelitian Iwan Amiruddin dan Wahyudin, menunjukkan bahwa $83,6 \%$ ibu hamil di Puskesmas Bantimurung mengalami anemia (Sulistyoningsih, 2011).

Berdasarkan data Riskesdas (2013) menunjukkan angka kejadian anemia pada ibu hamil adalah $37,1 \%$ dengan kadar $\mathrm{Hb}$ kurang dari 11,0 gram/dl, dengan proporsi yang hampir sama antara dikawasan perkotaan $(36,4 \%)$ dan perdesaan $(37,8 \%)$. Sedangkan penyebab tidak langsung kematian ibu karena 4 terlalu (terlalu muda, terlalu tua, terlalu sering melahirkan dan terlalu dekat kehamilan) dan 3 terlambat (terlambat mencapai rujukan, terlambat mengambil keputusan dan terlambat mendapat pertolongan tenaga kesehatan). Ini semua terkait dengan faktor akses, sosial budaya, pendidikan, dan ekonomi (Kemenkes RI, 2014).

Beberapa faktor yang mempengaruhi kejadian anemia pada ibu hamil salah satunya adalah paritas. Paritas adalah jumlah kehamilan yang menghasilkan janin yang mampu hidup diluar rahim. Menurut Husin, (2013) ibu yang melahirkan lebih dari 3 kali dapat menyebabkan anemia yaitu 8 hingga 9 kali. Hasil penelitian Herry Suswanti Djarot dan Siti Nurjanah menunjukkan bahwa 69,2\% ibu hamil yang anemia dengan paritas di Puskesmas Bangetayu Kecamatan Genuk Kota Semarang.

Selain paritas, pemberian tablet Fe juga berhubungan dengan kejadian anemia pada ibu hamil. Umumnya penyebab anemia pada ibu hamil adalah kurangnya gizi, kurangnya zat besi dalam makanan yang dikonsumsi, penyerapan yang kurang baik dan penyakit-penyakit kronik (seperti TBC, paru-paru, cacing usus, dan malaria). Ibu hamil dikategorikan mengalami anemia jika kadar haemoglobin pada pemeriksaan laboratorium < $10 \mathrm{gr} \%$ dan pada anamnesa didapatkan keluhan cepat lelah, sering pusing, mata berkunang-kunang dan muntah yang lebih hebat pada kehamilan muda (Sulistyoningsih, 2011). Penelitian Juslina dan Abdul Razak Thaha menunjukkan $23,4 \%$ ibu hamil anemia dengan defisiensi besi di Kecamatan ujung Tanah dan Kecamatan Biringkanaya Kota Makassar.

Menurut Laporan Rencana Kerja Pembinaan Gizi Masyarakat (RKPGM, 2013), Program penanggulangan anemia gizi pada ibu hamil telah dikembangkan melalui distribusi Tablet Tambah Darah (TTD). TTD merupakan suplementasi gizi mikro khususnya zat besi dan folat yang diberikan kepada ibu hamil untuk mencegah kejadian anemia gizi besi selama kehamilan. Pemberian zat besi sebanyak 30 gram per hari akan mening-katkan kadar hemoglobin 
sebesar 0,3 gr/dl per minggu atau dalam 10 hari (Sulistyoningsih, 2011).

Anemia pada kehamilan merupakan masalah nasional karena mencerminkan nilai kesejahteraan social ekonomi masyarakat, dan pengaruhnya sangat besar terhadap kualitas sumber daya manusia. Anemia kehamilan disebut "potential danger to mother and child" (potensi membahayakan ibu dan anak), karena itulah anemia memerlukan perhatian serius dari semua pihak yang terkait dalam pelayanan kesehatan (Manuaba, 2010). Anemia dalam kehamilan memberikan pengaruh yang kurang baik bagi ibu, baik dalam kehamilan, merupakan suatu pendekatan, observasi, atau pengum-pulan dan sekaligus pada satu saat, artinya setiap subjek penelitian hanya diobservasi sekali saja (Notoatmodjo, 2012).

Variabel bebas dalam penelitian ini adalah paritas, jarak kehamilan dan konsumsi tablet fed an Variabel terikat dalam penelitian ini adalah Anemia pada ibu hamil.bPopulasi dalam penelitian ini adalah seluruh ibu hamil yang berkun-jung di Puskesmas Tanjung Pinang yaitu berjumlah 371 orang ibu hamil.

Data primer adalah data yang diperoleh dengan melihat hasil $\mathrm{Hb}$ di Buku KIA dan wawancara menggunakan kuesioner dengan responden untuk men-dapatkan data tentang paritas, jarak kehamilan dan konsumsi tablet fe. Data sekunder adalah data yang didapat dari Kohort dan buku register Puskesmas Tanjung Pinang Tahun 2018. Instrument penelitian yang digunakan pada saat penelitian yaitu kuesioner. Analisa data analisa univariat dilakukan untuk mengetahui gambaran distribusi frekuensi variabel yang diteliti yaitu paritas, jarak kehamilan dan konsumsi tablet $\mathrm{Fe}$ serta analisa bivariat digunakan untuk me-ngetahui hubungan paritas, jarak kehamilan dan konsumsi tablet fe terhadap status anemia pada ibu hamil dengan menghitung Prevalensi Rate (PR) dan Chi-Square Test.

\section{HASIL PENELITIAN DAN PEMBAHASAN}

\section{Tabel 1}

Distribusi Frekuensi Kejadian Anemia pada Ibu Hamil di Wilayah Kerja Puskesmas

Tanjung Pinang Kota Jambi Tahun 2018

\begin{tabular}{lccc}
\hline $\begin{array}{l}\text { Kategori } \\
\text { Anemia }\end{array}$ & $\begin{array}{c}\text { Hb } \\
\text { (gram\%) }\end{array}$ & f & \% \\
\hline Tidak Anemia & $>11$ & 0 & 0 \\
Anemia Ringan & $9-10$ & 0 & 0 \\
Anemia Sedang & $7-8$ & 17 & 42,5 \\
Anemia Berat & $<7$ & 23 & 57,5 \\
\hline \multicolumn{2}{c}{ TOTAL } & 40 & 100 \\
\hline
\end{tabular}

Tabel .2

Distribusi Frekuensi Kejadian Anemia pada Ibu Hamil Berdasarkan Paritas di Wilayah Kerja Puskesmas Tanjung Pinang

Kota Jambi Tahun 2018

\begin{tabular}{ccc}
\hline Paritas & f & \% \\
\hline RisikoRendah & 18 & 45 \\
RisikoTinggi & 22 & 55 \\
\hline Jumlah & 40 & 100 \\
\hline
\end{tabular}

Tabel .3

Distribusi Frekuensi Kejadian Anemia pada Ibu Hamil Berdasarkan Jarak Kehamilan di Wilayah Kerja Puskesmas Tanjung Pinang Kota Jambi Tahun 2018

\begin{tabular}{ccc}
\hline JarakKehamilan & f & \% \\
\hline RisikoRendah & 17 & 42,5 \\
RisikoTinggi & 23 & 57,5 \\
\hline Jumlah & 40 & 100 \\
\hline
\end{tabular}


Tabel 4

Distribusi Frekuensi Kejadian Anemia pada Ibu Hamil Berdasarkan Konsumsi Tablet Fe di Wilayah Kerja Puskesmas Tanjung Pinang Kota Jambi Tahun 2018

\begin{tabular}{lcc}
\hline \multicolumn{1}{c}{ Pernyataan } & f & \% \\
\hline $\begin{array}{l}\text { Ibumengkonsumsi tablet besi } \\
\text { (Fe) padakehamilan. }\end{array}$ & 40 & 21,97 \\
$\begin{array}{l}\text { Tablet tambahdarah (TTD) } \\
\text { Mengkonsumsi tablet }\end{array}$ & 40 & 21,97 \\
tambahdarahdariPuskesmas & 40 & 21,97 \\
$\begin{array}{l}\text { Mengkonsumsi tablet } \\
\text { tambahdarah } \leq 90 \text { tablet }\end{array}$ & 35 & 19,23 \\
$\begin{array}{l}\text { Minum tablet } \\
\text { tambahdarahdengan air putih. }\end{array}$ & 27 & 14,83 \\
\hline \multicolumn{1}{c}{ Jumlah } & 182 & 99,97 \\
\hline
\end{tabular}

Tabel 5

Hubungan Paritas dengan Kejadian Anemia pada Ibu Hamil di Wilayah Kerja Puskesmas Tanjung Pinang Tahun 2018

\begin{tabular}{|c|c|c|c|c|c|c|}
\hline \multirow[t]{2}{*}{ Paritas } & \multicolumn{4}{|c|}{ Anemia } & \multirow{2}{*}{$\begin{array}{l}\text { To } \\
\text { tal }\end{array}$} & \multirow{2}{*}{$\begin{array}{c}P- \\
\text { Value }\end{array}$} \\
\hline & $\begin{array}{l}\text { Se } \\
\text { da } \\
\text { ng }\end{array}$ & $\%$ & $\begin{array}{l}\text { Be } \\
\text { rat }\end{array}$ & $\%$ & & \\
\hline $\begin{array}{c}\text { Risikore } \\
\text { ndah }\end{array}$ & 13 & 76,5 & 5 & 21,7 & 18 & \\
\hline $\begin{array}{c}\text { RisikoTi } \\
\text { nggi }\end{array}$ & 4 & 23,5 & 18 & 78,3 & 22 & 0,002 \\
\hline Jmlh & 17 & 100 & 23 & 100 & 40 & $\begin{array}{l}\mathrm{OR}= \\
11.70\end{array}$ \\
\hline
\end{tabular}

Hasil uji statistik di peroleh nilai pvalue 0.002 . Berarti jika p-value $<0,05$ maka Ho ditolak sehingga dapat diartikan bahwa terdapat hubungan yang signifikan antara paritas dengan kejadian anemia pada ibu hamil. Dari hasil analisis diketahui nilai odds ratio $=11,700$ pada rentang 2,621-52,219, artinya ibu hamil dengan kelompok paritas risiko tinggi mempunyai risiko 11,700 kali untuk mengalami anemia berat
Tabel 6

Hubungan Jarak Kehamilan dengan Kejadian Anemia pada Ibu Hamil di Wilayah Kerja Puskesmas Tanjung Pinang Tahun 2018

\begin{tabular}{|c|c|c|c|c|c|c|}
\hline \multirow{2}{*}{$\begin{array}{l}\text { JarakKe } \\
\text { hamilan }\end{array}$} & \multicolumn{4}{|c|}{ Anemia } & \multirow{2}{*}{$\begin{array}{l}\text { To } \\
\text { tal }\end{array}$} & \multirow{2}{*}{$\begin{array}{c}P- \\
\text { Value }\end{array}$} \\
\hline & $\begin{array}{l}\text { Se } \\
\text { da } \\
\text { ng }\end{array}$ & $\%$ & $\begin{array}{l}\mathrm{Be} \\
\text { rat }\end{array}$ & $\%$ & & \\
\hline $\begin{array}{c}\text { Risikore } \\
\text { ndah }\end{array}$ & 13 & $\begin{array}{c}76,4 \\
8\end{array}$ & 4 & $\begin{array}{c}17,3 \\
9\end{array}$ & 17 & 0,001 \\
\hline $\begin{array}{l}\text { Risiko } \\
\text { Tinggi }\end{array}$ & 4 & $\begin{array}{c}23,5 \\
2\end{array}$ & 19 & $\begin{array}{c}82,6 \\
0\end{array}$ & 23 & $\mathrm{OR}=$ \\
\hline Jmlh & 17 & 100 & 23 & 100 & 40 & 15,43 \\
\hline
\end{tabular}

Hasil uji statistik di peroleh nilai p-valuenya p-value 0.001 . Berarti jika p-value $<0,05$ maka Ho ditolak sehingga dapat diartikan bahwa terdapat hubungan yang signifikan antara jarak kehamilan dengan kejadian anemia pada ibu hamil. Dari hasil analisis diketahui nilai odds ratio $=15,483$ pada rentang 3,260-73,107 artinya ibu hamil dengan kelompok jarak kehamilan risiko tinggi mempunyai risiko 15,483 kali untuk mengalami anemia berat.

Jarak kehamilan terlalu dekat yaitu kurang dari 2 tahun. Menjadi resiko karena sistem reproduksi belum kembali seperti keadaan semula sebelum hamil. Risiko jarak kehamilan terlalu dekat dapat menyebabkan terjadinya anemia. Hal tersebut karena tubuh seorang ibu belum cukup untuk mengumpulkan cadangan nutrisi setelah melalui hamil pertama (Husin, 2013). 
Tabel 7

Hubungan Konsumsi Tablet Fe dengan Kejadian Anemia pada Ibu Hamil di Wilayah Kerja Puskesmas Tanjung Pinang Tahun 2018

\begin{tabular}{c|c|c|c|c|c|c}
\hline \multirow{2}{*}{$\begin{array}{c}\text { Konsum } \\
\text { si Tablet } \\
\text { Fe }\end{array}$} & $\begin{array}{c}\text { Se } \\
\text { da } \\
\text { ng }\end{array}$ & $\%$ & $\begin{array}{c}\text { Be } \\
\text { rat }\end{array}$ & $\%$ & $\begin{array}{c}\text { To } \\
\text { tal }\end{array}$ & $\begin{array}{c}\boldsymbol{P} \text { - } \\
\text { Value }\end{array}$ \\
\hline Baik & 5 & 29,4 & 0 & 0 & 17 & \\
$\begin{array}{c}\text { Kurang } \\
\text { Baik }\end{array}$ & 12 & 70,6 & 23 & 100 & 23 & 0,022 \\
\hline Jmlh & 17 & 100 & 23 & 100 & 40 & $\begin{array}{c}\text { OR }= \\
1,417\end{array}$ \\
\hline
\end{tabular}

Hasil uji statistik di peroleh nilai p-value 0,022. Berarti jika p-value $<0,05$ maka Ho ditolak sehingga dapat diartikan bahwa terdapat hubungan yang signifikan antara konsumsi tablet $\mathrm{Fe}$ dengan kejadian anemia pada ibu hamil. Dari hasil analisis diketahui nilai odds ratio $=1,417$ pada rentang 1,042-1,925 artinya ibu hamil dengan kelompok konsumsi tablet Fe kurang baik mempunyai risiko 1,417 kali untuk mengalami anemia berat.

Kebutuhan $\mathrm{Fe}$ meningkat selama hamil untuk memenuhi kebutuhan $\mathrm{Fe}$ akibat peningkatan volume darah, untuk menyediakan $\mathrm{Fe}$ bagi janin dan plasenta, dan untuk menggantikan kehilangan darah saat persalinan. Peningkatan absorbsi Feselama trimester II kehamilan membantu peningkatan kebutuhan. Untuk ibu hamil, minumlah satu tablet tambah darah setiap hari paling sedikit selama 90 hari masa kehamilan dan 40 hari setelah melahirkan (Syafiq, 2013).

\section{KESIMPULAN DAN SARAN}

Ada Hubungan yang Bermakna antara Faktor Paritas dengan Kejadian Anemia pada Ibu Hamil di Wilayah Kerja Puskesmas Tanjung Pinang Kota Jambi Tahun 2018 dengan p-value 0,002. Ada Hubungan yang Bermakna antara Faktor Jarak Kehamilan dengan Kejadian Anemia pada Ibu Hamil di Wilayah Kerja Puskesmas Tanjung Pinang Kota Jambi Tahun 2018 dengan p-value 0,001. Ada Hubungan yang Bermakna antara Faktor Konsumsi Tablet Fe dengan Kejadian Anemia pada Ibu Hamil di Wilayah Kerja Puskesmas Tanjung Pinang Kota Jambi Tahun 2018 dengan p-value 0,022 .

Disarankan kepada pihak Puskesmas Tanjung Pinang khususnya petugas ruang kebidanan (KIA) dapat meningkatkan penyuluhan kepada remaja, PUS (pasangan usia subur) dan ibu hamil terutama tentang komplikasi pada anemia pada ibu hamil dengan mengembangkan program KIE (komunikasi, informasi, edukasi, dan konseling) mengenai penenganan secara dini tentang komplikasi yang mungkin terjadi sehingga AKI dan AKB dapat menurun.

\section{DAFTAR PUSTAKA}

Aristman. Gizi Dalam Daur Kehidupan. Jakarta: EGC; 2010.

Asriyah. Faktor-faktor yang Berhubungan dengan Anemia Pada Ibu Hamil di Wilayah Kerja Puskesmas Bajeng Kecamatan Bajeng Kabupaten Gowa Tahun 2012.

Febriana. Faktor-faktor yang Berhubungan dengan Kejadian 
Anemia pada Ibu Hamil di Puskesmas Gandus Palembang Tahun 2010.

Hidayat. Metode Penelitian Kebidanan dan Teknik Analisis Data. Jakarta Salemba Medika; 2010.

Husin. Asuhan Kehamilan Berbasis Bukti Paradigma Baru Dalam Asuhan Kebidanan . Jakarta: SS; 2014.

Kemenkes RI. Profil Kesehatan Ibu Tahun. Senin 10 maret 2018. 18:15 Wib.

http://kti kartini/Hasil Riskesdas 2013 Terkait Kesehatan Ibu.htm

Manuaba. Ilmu Kebidanan Penyakit Kandungan dan KB. Jakarta: Karisman; 2010.

Margareth. Kehamilan, Persalinan, dan Nifas. Yogyakarta: Nuha Medika; 2013.

Notoatmodjo. Promosi Kesehatan dan Perilaku Kesehatan. Jakarta: Rineka Cipta; 2012.

\section{- Metodologi Penelitian} Kesehatan. Jakarta: Rineka Cipta; 2010.

Proverawati. Anemia dan Anemia Kehamilan. Yogyakarta: Nuha Medika; 2011.

Saifuddin. Ilmu Kebidanan. Jakarta: PT Bina Pustaka; 2010.

Salmariantity, Faktor-faktor yang Berhubungan dengan Anemia Pada Ibu Hamil di Wilayah Kerja Puskesma Kabupaten gajah Mada Tembilahan Bajeng Kecamatan Bajeng Kabupaten Indragiri Tahun 2012.

Saryono, dkk. Asuhan Kebidanan I Kehamilan. Yogyakarta: Numed; 2010.

Soebroto,Ikhsan. 2010. Cara Mudah Mengatasi Problem Anemia. Jogjakarta: Bangkit.

Sulistyoningsih, H. Gizi untuk Kesehatan Ibu dan Anak. Yogyakarta: Graha Ilmu; 2011. 